\title{
Comparative Review and Analysis of Organizational (In)Efficiency Indicators in Qatar
}

\author{
Abdulla S. Al-Shaiba, Sami G. Al-Ghamdi *(i) and Muammer Koc ${ }^{(1)}$ \\ Division of Sustainable Development, College of Science and Engineering, Hamad Bin Khalifa University, \\ Qatar Foundation, Doha 34110, Qatar; abdalshaiba@mail.hbku.edu.qa (A.S.A.-S.); mkoc@hbku.edu.qa (M.K.) \\ * Correspondence: salghamdi@hbku.edu.qa; Tel.: +974-4454-2833
}

Received: 19 September 2019; Accepted: 16 October 2019; Published: 21 November 2019

\begin{abstract}
Organization efficiency is a pivotal paradigm for an organization's profitability in short-term cycles and long-term sustainability as a responsible stakeholder of a society. Measurement of organizational efficiency primarily depends on tracking the performance of the organization based on key performance indicators established commonly and differently by sectors. Literature on measuring organizational efficiency is limited in quantity and qualitatively poor, specifically on organizations operating in the Middle East and the Arabian Gulf where specific culture and traditions take precedence. This paper brings about a comparative review on organizational efficiency models, measurements, and indicators based on international best practices and conduct a comparative analysis from the Qatari organizational context. The methodology involved in measuring and benchmarking organizational sustainability identify the "as is" state of organizational sustainability and efficiency in the organization. Identifying the best sustainability practices across peer organizations and equipping organizations with the appropriate tools and skills to implement the identified best practices to fill the efficiency gap is essential. Defining and benchmarking indicators with peer organizations help the management to understand the "as is" state of the organization and is the impetus for the advancement of short- and long-term sustainability goals. The key performance indicators and focal themes for air transport, electricity-public utility, oil and gas, retail banking, and steel manufacturing are compared and identified.
\end{abstract}

Keywords: organization efficiency; comparative analysis; organization efficiency indicators

\section{Introduction}

The literature on measuring organizational efficiency is limited in quantity and qualitatively poor compared with the literature available on organization efficiency models and factors impacting organizational efficiency. There are lots of models and frameworks related to measuring organizational effectiveness and efficiency. However, identifying a suitable one is stressful for management in most organizations. One of the most widely accepted and applied measures for organization performance were efficiency and effectiveness, both of these terms have various distinct meanings and contexts in which they are applied [1].

The authors of this study aim to compare the organizational efficiency indicators used by Qatari organizations and with international best practices to understand and reveal the root-causes of perceptional inefficiencies clearly and systematically.

In order to accomplish the determined research objective and to answer the research question systematically and scientifically, the research approach followed was to conduct a comprehensive exploratory literature review to understand the organizational (in)efficiency; its impacts; efficiency metrics and indicators; and best practices and management tools to improve organizational efficiency in Qatari organizations. 
Performance parameters of Qatar Steel and Qatar Petroleum that were available in the public domain through annual reports and sustainability reports for 2016 were compared with POSCO and Shell PLC. Both POSCO and Shell are considered the best in class performers in steel manufacturing and petroleum verticals [2].

The oil and gas organizations in Qatar can be seen as the leading organization in Qatar that focus in increasing the efficiency level of their organizations by following and implementing different tools and methods. Similarly, the performance of Shell PLC and Qatar Petroleum was compared to find average productivity per FTE. Average productivity per employee of Shell was 14586.95 BOE (Barrel oil equivalent). In case of Qatar petroleum, average productivity per employee was 4195.73 BOE.QP, average productivity per FTE lagged by around 10,391 BOE per year.

Efficiency represents ability to optimally manage its resources and is tracked by indicators like cost of production per unit and headcount [3]. In the case of the steel industry, productivity per employee is considered as a standard indicator, which is calculated by dividing total production in tons by the total number of employees. POSCO's average productivity per head was 1553.14 tons per FTE, whereas Qatar Steel's average productivity per head during the same period was 1101.88 tons-a difference of over 450 tons of steel per employee per year which is significant as Qatar Steel operates in a limited market [4]. Qatar Steel has been making efforts for ensuring effective and efficient deployment of existing resources for capability maximization. Some of the key avenues of internal resource optimization include process re-design for efficiency, technology up-gradation, workforce planning, role clarification, goals cascading, skill alignment, cross functional/departmental communication, organization de-layering, and team based governance [5]. The following sections of this paper explore the efficiency parameters of Qatari organizations in comparison with their peers internationally to benchmark the efficiency indicators and identify improvement areas.

\subsection{Background}

Most organizations measure performance in terms of effectiveness, which focuses on achieving their mission, vision, and strategic objectives. However, other organizations measure their efficiency in terms of resource utilization to achieve the desired objectives including their vision, mission, and operational goals. Efficiency is defined as the ratio of useful work generated and total energy or resources used to generate useful work or output. Effectiveness is defined as an organization's ability to attain goals; hence, it includes efficiency and adaptability to future conditions. Efficiency also quantifies investments and efforts to achieve an organization's goals, and effectiveness evaluates impacts or results of investments and efforts [6].

However, this definition could be generalized in the context of organizations. There is a difference between business efficiency. In this context, business refers to the popular commercial, industrial, or professional activities that can generate economic outcomes and organizational efficiency. The former could be measured as a ratio between inputs and outputs of business operations. However, organizational efficiency not only reflects on the state of the business processes but also considers the governance and cultural effectiveness along with the impact it creates on the value chain. A comparison of the definitions of both terms demonstrates that business efficiency is linked to profitability and growth of a business in financial terms, and organizational efficiency indicates the overall health of the organization in a holistic manner, including economic benefits, environmental supremacy, and social responsibility. The focus of this research is organizational efficiency [7].

Organization efficiency relies on various functions that must follow and be implemented within an organization for that organization to become efficient. In this section, the author studies and summarizes modes that address organizational efficiency. The organizational efficiency models have evolved from a construct perspective, and performance measurement and management models have evolved from a process perspective [8].

As per organization efficiency experts such as Brovkin (2004), organization efficiency can be defined as the capability of an organization to fulfill its objectives with minimum resource utilization. 
Resource utilization includes raw materials, financial resources, human resources, and technological resources. Efficiency can be measured as a ratio between output and input, but organizational efficiency is also reported in monetary terms [9].

\subsection{Measuring Organization Efficiency in the Qatari Context}

Few researchers have investigated a direct correlation between organizational efficiency and corporate performance. "The greater the organizations' efficiency and effectiveness, the higher are its chances for continued (sustained) economic survival" [10]. Some of the researchers identified seven dimensions for measuring the efficiency of an organization:

- Organizational strategy;

- Organizational structure;

- Buildup of management and business systems;

- Development of the corporate and employee culture;

- Employee motivation;

- Training of employees;

- Goal-setting for employees.

Conventionally, these dimensions cover a wide range of organizational functions, such as leadership, governance, human development and engagement, corporate citizenship, business, and operational excellence, and supply chain management [11].

Measurement of organizational efficiency primarily depends on tracking the performance of the organization within the following scopes:

- Monitoring progress of operational processes: Operational processes can be tracked to measure the throughput, process cycle time to deliver the output along with the quality of the output. This measure shows the health of the process;

- Monitoring implementation of the strategy: Implementation of strategy depends on establishing clear goals, timelines, resource requirements, and responsibilities. Once KPIs are identified, tracking the implementation of the strategy becomes easy.

Organizational effectiveness was considered a construct throughout the 1980s but is now considered more of a concept [12].

The concept intends to understand how an organization accesses its resources and processes and produces results to achieve its operational and strategic goals within specified periods [13]. One of the prominent researchers of organizational effectiveness, Cameron (1978), asserted that organizational effectiveness is the proficiency of the organization to access essential resources [14]. McCann (2004) defined organizational effectiveness as the criteria for the organization's successful fulfillment of the purposes through its core strategies.

The author posits that organization efficiency could be measured by tracking both the effectiveness and efficiency-related parameters of an organization. These parameters could be grouped as external factors such as customers, suppliers, and competition and internal factors such as leadership, strategy, quality, performance management, and employee satisfaction, use of IT, innovation, and corporate governance. Using relevant metrics to track these parameters would be the impetus for the measurement of organization efficiency [15].

Qatari organizations follow the best practice processes for most business operational domains, but in some areas such as human resources, the processes deviate from the norm because of the inequitable nature of its prevailing traditions, customs, and organization culture, which are also practiced in the Arabian Gulf in general.

Fundamental differences with assessments using either effectiveness or efficiency measures ties to the fact that effectiveness is a broad topic, covering innovation, quality of goods or services, employee satisfaction, customer satisfaction, and organizations interaction with the surrounding community, 
its social and economic environment. However, efficiency measures the relationship between inputs and outputs or how maximum output is generated with minimum inputs. The findings of various studies reveal that effective yet inefficient organizations might continue to survive, while ineffective yet efficient ones will move toward bankruptcy sooner or later. Explicit references in literature to a Middle Eastern context were missing.

Balduck and Buelens (2008) asserted that organization effectiveness could be assessed through one of four approaches: The system resource approach, the goal approach, the strategic constituency approach, and the internal process approach [16]. These models are discussed in the subsequent sections. Various models have been developed to map organizational efficiency. A few of the prominent models are discussed as follows:

The Kilman and Herden Model of organizational effectiveness proposed the paradigm of integrating psychological and social dimensions of well-being as a parameter for measuring success of organizations. They define corporate efficiency as a multiple of internal efficiency (maximum output for minimum input); internal effectiveness (maximum motivation of stakeholders including employees), external efficiency (maximized bargaining positions in exchanges), and external effectiveness (maximize societal satisfaction). The parameters that reflect the internal and external dimensions of corporate efficiency are shown in Figure 1. Notably, this list is a representative example to show the significance of each quadrant of corporate performance, and not an exhaustive list [17].

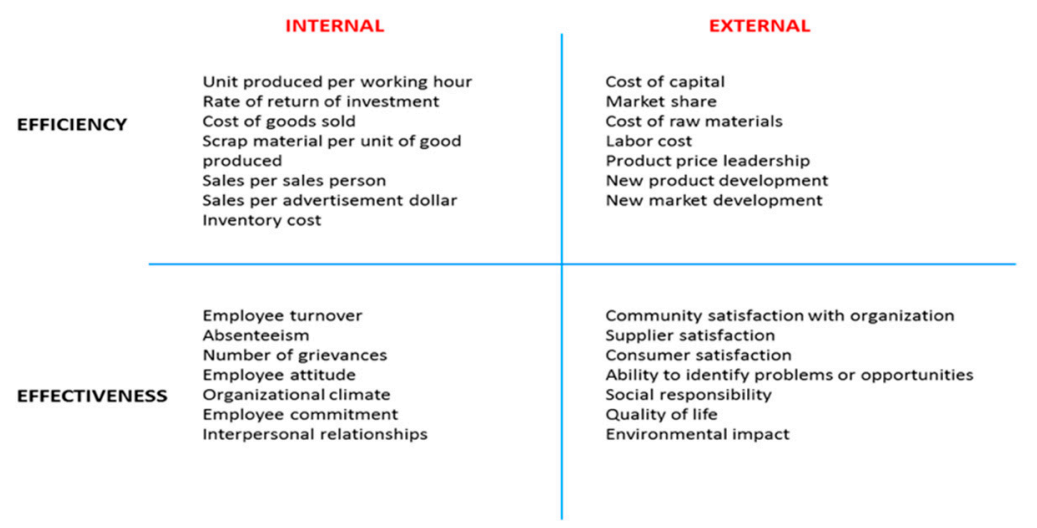

Figure 1. Kilman-Herder parameters for organization efficiency mapping [18].

An example of the Kilman-Herden model of organizational efficiency is shown in Figure 2. The model calculates organizational efficiency as multiple of averages ratings obtained by parameters evaluated in each quadrant, as explained in the previous section.

Organizational Efficiency $=($ Internal Efficiency $X$ External Efficiency $X$ Internal Effectiveness $X$ External Effectiveness).

Process approach model: The process approach model focuses on the transformation processes and extent of resources employed to turn the inputs into goods and services. In this model, efficiency is measured based on the performance of the business and operational processes systematically tracked and reported through appropriate performance indicators. The success of such models primarily depends on the relationship between various stakeholders and the flow of information in vertical and horizontal reporting lines. The links between processes within one department and across multiple departments may successfully drive organizational transformation. This model is mostly employed with organizations that produce goods and services and may not be completely fit for organizations operating in the "nonprofit" domain because the output may not be quantified and cannot always be linked to business and operational processes. Strategic Constituency Model: The strategic constituency model aims to approach the ability and effectiveness of an organization to fulfill the interests of various stakeholders or influence groups [19]. 


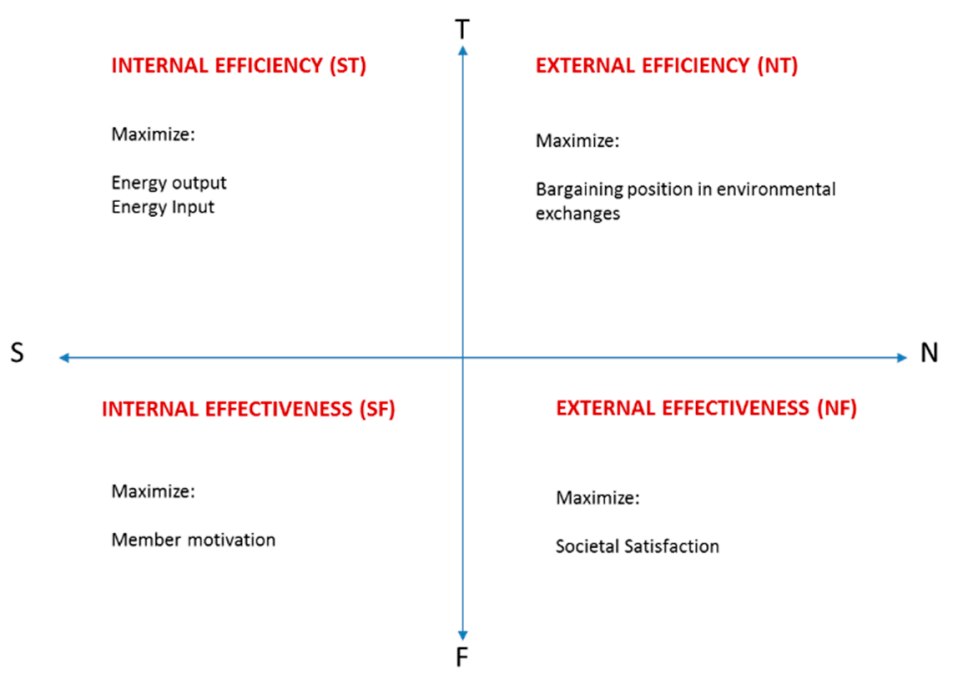

Figure 2. Kilmann-Herder model for evaluating organization efficiency [18].

The effectiveness of an organization, according to the strategic constituency model, mainly relies on the minimum satisfaction of all the strategic constituencies of an organization. The strategic constituency of an organization includes all the individuals linked with the organization in various capacities, for example, the investor community, suppliers and partners in the supply chain, employees, regulators, government, customers, and environment [20].

The strategic constituency model could apply to organizations where the relation between the stakeholders could not be quantified in a cost-benefit relationship, such as corporate social responsibility (CSR). The model is particularly helpful to understand the expectations of society and benefits generated for society, which are difficult to capture in other models. Notably, various strategic constituencies may not always agree with each other on common interests, namely, the expectations may sometimes be exactly the opposite from one constituency to another. For example, for an organization in the manufacturing sector, increased production generates more profits for investors and management but also can cause an increase in waste and pollution generated from the manufacturing operations. In this type of conflicting scenario, organizational efficiency, according to this model, ensures the minimum satisfaction level of the opposing strategic constituencies [20].

An alternative model to monitor organizational efficiency was proposed by Bernard Bass. In this model, an organization's performance or worth could be assessed based on three key parameters [21]:

1. Degree of productivity, profitability, and self-maintenance;

2. Degree to which an organization adds value to its member and stakeholders;

3. Degree to which an organization and its members are a value to the society.

Sink and Tuttle (1989) proposed a similar framework for measuring organizational performance and efficiency through six parameters:

1. Effectiveness: The bottom line of organizational performance and efficiency;

2. Efficiency: Resource consumption versus output generation;

3. Quality: Internal quality (fulfilling internal process requirements) and external quality (fulfilling customer requirements and expectations);

4. Timeliness: Three key time parameters to establish organizations' efficiency-cycle time (time to complete one iteration of an operational process), waited time (time lag experienced by the customer to receive a product or service), and completed on time (tasks completed on time considering internal or external timelines);

5. Finance: Profitability and spending according to budgets are two critical criteria of organizational efficiency from finance perspective; 
6. Workplace environment: Physical amenities for employees and organizational culture constitute workplace environment [22].

In a comparison of the aforementioned models, two models standout for their direct approach and ease of implementation:

1. The Bass model measures three key parameters: (a) Profitability, (b) value creation for stakeholders, and (c) value creation for society; and

2. Sink and Tuttle's model signifies the importance of measurable parameters such as timeliness, quality, efficiency and effectiveness, profitability, and employee satisfaction in establishing organization efficiency.

To benefit from both models, a combination of these two models is used to establish indicators for measuring organizational efficiency

\subsection{Factors Affecting Organization Efficiency}

Many factors influencing successful organizational transformation improve the efficiency level within that organization (Figure 3).
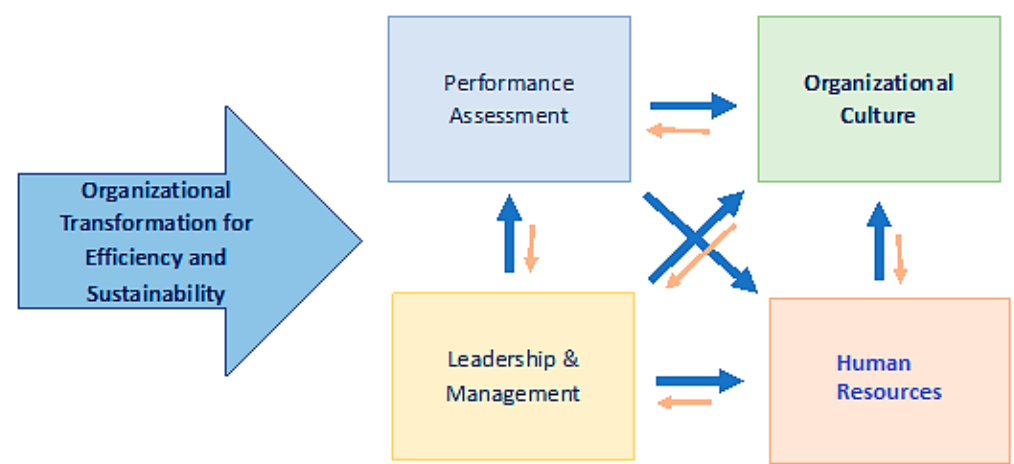

Figure 3. Important factors and ingredients of organization transformation and efficiency, after [23].

Three key resources that affect an organizations' performance are human resources, financial resources, and physical and infrastructure resources [24]. The organization's performance is directly dependent on its human resources as enablers to achieve its objectives. Human capital plays an essential part in strategic planning to create a competitive advantage. A firm's human capital has two dimensions: Value and uniqueness. Resources are valuable when they allow the firm to improve effectiveness, capitalize on opportunities, and reduce threats. In the context of effective management, value focuses on increasing profits compared with the associated costs [25].

Research analyzed the relationship between human capital and organizational performance in software companies and revealed a positive correlation. The key features of human capital development they highlight include trainings attended and teamwork practices [26]. Some researchers stated that efficiency of an organization is not related to authoritarian leadership but to the culture of the organization, which is responsible for employee satisfaction, motivation, and high performance [27]. An organization's success heavily depends on the number of human efforts in an organization and its organizational structure-assisted by efficient use of its hardware/software resources to achieve the objectives. Hence, maintaining a highly motivated and satisfied workforce and the optimal organizational structure is essential for successful organizations [28].

The literature on factors affecting organization efficiency lists varied factors from diverse spheres within the organization's operation and governance. However, most of the factors are linked to Human Resources which signify the single most important factor in the success of any organization. The factors discussed in the literature talk about organizational flexibility to address employee 
concerns and provide a minimum level of employment security as few important factors affecting organizational efficiency.

Organization structure is a bridge between human resources and the organization by rationalizing the distribution of jobs, power, and compensation based on the specialization of skills required to deliver the expected results. The most critical factor affecting the productivity of human resources within an organization is the organization structure. While the organization's success heavily depends on the number of human efforts in an organization, its organizational structure is aided by the efficient use of its hardware/software resources to achieve the objectives. Wrong organization structure could lead to disastrous results. The author feels that there are two facets to suboptimal organization structure: (i) Not providing the best suited designation/job role of an eligible employee thereby impacting his/her motivation, productivity, and satisfaction, and (ii) posting wrong candidates (candidates without the right skill sets for the job role) for a specific job would be tantamount to setting up the employees for failure as organizational structure is the means to distribute power, resources, and compensation fairly to the staff of an organization [29].

If the roles, responsibilities, remuneration, and power are not rationally distributed, disgruntlement and dissatisfaction occur among employees, leading to a significant impact on productivity. By contrast, organizations with an optimal organization structure excel in productivity and have significantly high ratings for employee motivation and satisfaction. Thus, increased productivity in an organization has a direct economic impact on the stakeholders and the socioeconomic benefits offered to the community by the highly satisfied and motivated employees [30].

Performance of an employee could be affected by many factors. The organizational culture, leadership styles, and corporate communication are few important factors that could impact organization efficiency. The author feels that these entire factors link to the human aspect linked to workforce psychology that eventually affects an employee's motivation and, in turn, better or worse performance leading to impact organization's efficiency in a positive or negative way. Organizational justice is a core factor that affects an employee's morale and, thus, performance [31].

The employees could be anxious or concerned about organizational justice being imparted. It also affects an employee's motivation, satisfaction, and commitment to the organization. Employees prefer fair and equal treatment within their organization. The productivity and commitment of the employees toward their organization increase if they perceive the treatment they receive is equal and fair in relation to their work. Organizational justice is proportional to the staffs' perception of fair treatment at work [32].

Organization culture and an organization's leadership are intertwined topics because of the high degree of interdependency and impact on an organizations' performance. Because an organization typically intends to improve its operational performance, the leadership styles of its managers should be critically analyzed to understand any flaws and coached to adapt to situations requiring a turnaround of organizational performance. The authors defined leadership as "the art of motivating a group of individuals to act toward achieving a common goal." William Cohen 2010 stated that "leadership is all about results." Measuring the effectiveness of the leadership as effective leadership is difficult because the assessment is based on many variables and facets of personality. Some key factors associated with leadership are ethics, personal values, intellect, creativity, knowledge, confidence, communication skills, courage, and leader's charisma [33].

In summary, a good leader must have all these basic traits in varying degrees and should be emotionally intelligent to make the best out of any situation presented without compromising on the sense of purpose and motivation to achieve the goals set. A good leader shares the credit of success with subordinates and takes responsibility for failure. The management literature has listed many leadership styles, for example, autocratic, bureaucratic, charismatic, democratic/participative, laissez-faire, people-friendly leadership/relation oriented leadership, transformational leadership, task-oriented leadership, servant leadership, and transactional leadership. Different styles of leadership have different impacts on organizational performance. Notably, few of these leadership styles help 
organizations succeed, transform, and achieve goals, and some leadership styles hinder an organizations' development and are thus a source of employee demotivation and dissatisfaction [34].

The autocratic leadership style has the most negative impact on an organization's performance. In this form of leadership, a leader exercises immense power over the staff of an organization and offers little to no opportunities for the staff to voice their opinions or be involved in decision-making processes. In most organizations, autocratic leaders produce dismal performance. Contrary to the autocratic style, transformational leadership is one of the most successful leadership styles: The leader is a role model who inspires staff by challenging them to reach their true potential through increased commitment to the organization. Transformational leaders assess the strengths and weaknesses of their staff and delegate responsibilities according to strengths to balance the workload and responsibilities and optimize the organization's performance and productivity. Leadership style is also related to the organization's culture.

In summary, the failure or success of an organization is heavily dependent on the leadership style and its culture, including the beliefs, values, opportunities, and constraints of an organization at any given point in time. The importance of a leader is observed, for example, when the leader successfully navigates the organization through challenging market conditions [34].

Employee training and corporate communication also figures as few of the important factors affecting organization efficiency. Training is one of the most important functions of human resources management in an organization. This area is one of the few areas where the interests of an organization's management and its employees converge. From an organization perspective, upskilling employees so that they can perform to their highest potential benefit the organization's efforts to increase and sustain its productivity. In a similar manner, training opportunities for employees help them advance in their careers and realize better compensation and opportunities [26]. Research on health services sector organizations across South Asian countries revealed that training was a prominent factor that affects employee motivation and job satisfaction [35]. Although employee performance is linked to many facets such as job satisfaction, compensation, and benefits, a strong positive correlation was observed between the performance of an organization and their learning development (i.e., training) budget. Training budgets have widely been observed to be one of the first to get reduced in the case of cost reduction. However, other results revealed that organizations should invest in training as a tool to improve employee motivation and satisfaction, which increased employee productivity [35].

The importance of human capital development for organizational efficiency is critical to the extent that Adam Smith, the father of modern economics, included human capacities in his conception of capital stock in 1776. Notably, in the late 1950s and 1960s, the importance of human capital began to be featured prominently in the literature. Schultz considered the investment in education and training to build up a stock of skills and abilities (human capital) in the population that can benefit national economies and fuel economic growth. Moreover,, Schultz proposed a five-fold strategy for investment in human resources: Improve health facilities and services to increase life expectancy, strength, and stamina; in-service or on-the-job training; formal education at the primary, secondary, and tertiary levels; adult literacy programs for individuals who missed formal education; and migration of individuals and families to adjust to changing job opportunities [36].

Harbison (1962) argued that human resources establish the ultimate basis for the wealth of nations. He described financial capital and natural resources as passive factors of production and human beings as active agents that use these passive resources to build economic, social, and political organizations and promote national development [37].

In addition, evidence showed that the relevance of human capital to a firm's performance has become prevalent among the technology-based new ventures, and the use of human capital tools (emphasizing quality of employees) in small technology-based new ventures tend to have a significant impact on firms' success. Another visible element in the success of an organization is the ability of its leadership to foresee changes proactively and prepare the organization to absorb the changes [38]. 
The leadership obtains its moral license to steer and transform an organization to a sustainable path through its relationship with the employees. The values and culture of an organization develop a relationship of trust among the two parties that results in highly motivated and engaged staff. The leadership uses various channels to convey its vision across the board [39].

One of the modern tools that have been adopted to improve communication within organization is blogging. Organizations are increasingly encouraging employees to communicate with their supervisors and leadership through blogging. Providing employees with the opportunity to express themselves through a blog allows them to actively contribute to the operation of the organization, share their opinions, and ask questions. This process improves internal communication and offers employees a sense of ownership-"we are being heard" [40].

Process management, innovation, and efficiency in operations are important factors affecting organizational efficiency from a business process perspective. Implementation of tools like six sigma and lean would help improve efficiency. However, these initiatives and tools are not always successful in maintaining productivity while initiating process changes. Researchers Ahire et al. (2000) state that results of research on the impact of process management efficiency while maintaining productivity has been dismal. Authors agree to this, as the process changes impacts workforce and there exists a learning curve to accept and imbibe process changes, leading to temporary productivity losses throughout the learning curve [41].

As stated earlier, the authors feel that the key factors affecting organization efficiency are directly or indirectly linked to workforce psychology and affects employee motivation and satisfaction significantly, which would make or break any organizational transformation initiatives.

\subsection{Limitations of Research}

Though there exist many kinds of literature about organizational effectiveness, there is no concrete definition or approach of measuring organization effectiveness. Many organizational efficiency (OE) models and their varying definitions point toward difference of opinion and perspective on organizational effectiveness. This lack of a uniform approach makes choosing an OE model for measurement of organizational efficiency even more difficult in the context of Qatari organizations.

\section{Review Methods}

\subsection{Measuring and Benchmarking Organizational Sustainability and Efficiency}

Organizational sustainability indicators measure critical operational aspects of an organization. Essential tasks involved in measuring and benchmarking organizational sustainability are as follows:

- Identify "as is" state of organizational sustainability and efficiency in the organization;

- Identify best sustainability practices across peer organizations;

- Equip the organization with the appropriate tools and skills to implement the identified best practices to fill the efficiency gap.

Defining and benchmarking indicators with peer organizations helps the management to understand the "as is" state of the organization and to advance short- and long-term goals [42]. Some world-renowned organizational sustainability champions have argued that organizations "do well by doing good" and add to their customer base and brand value by being "less evil" [43].

Organizational sustainability is a process that begins with a focus on the following four dimensions:

- Strategic sustainability-realistic vision and goals established;

- Product and program sustainability-high-quality products, services, and programs developed;

- Personnel sustainability-personnel can effectively and reliably perform to fulfill their KPIs;

- Financial sustainability-profit generation as per agreed targets, adequate financial reserves, contingency planning, and positive cash flow to maintain sustained operation [44]. 
Santos, Anunciaco, and Svirina (2013) proposed an alternative model (Figure 4) to measure organizational sustainability known as DPOBE (Direction, Posture, Organization, Behavior, and Evaluation).

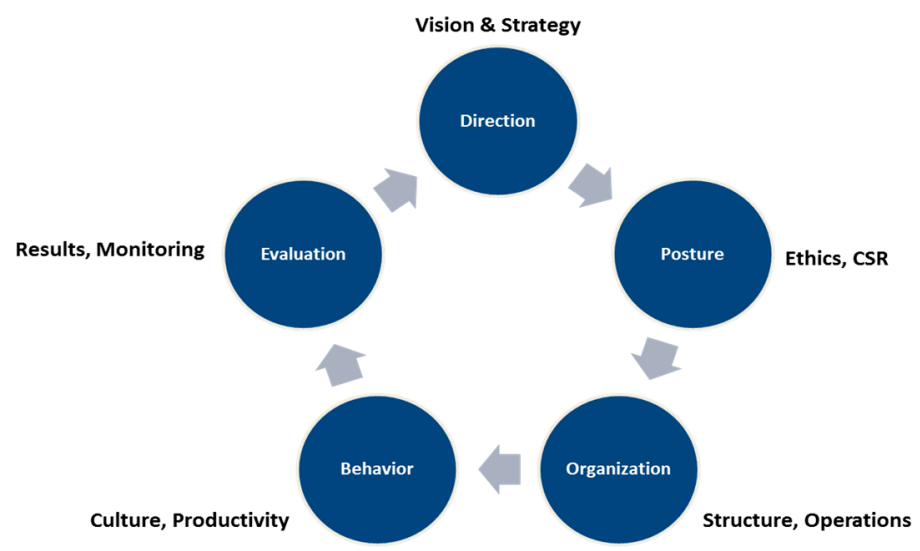

Figure 4. Direction, Posture, Organization, Behavior, and Evaluation (DPOBE) model for organizational sustainability [45].

The DPOBE model uses five parameters to map the sustainability of an organization. The details of parameters are as follows:

- Direction: In analyses of the economic health of the organization, the capacity to conceive and visualize strategic goals and developing plans to achieve them through encouraging innovation within the organization;

- Posture: Conduct of the management should be ethical to garner credibility and respect for the organization and to inculcate good attitudes and key behaviors that foster a performance culture and innovation to ensure the development of a balanced economy and society;

- Organization: Parameters measure the management activity of the organization in managing various process systems and technologies in the context of financial results and alignment to business strategies;

- Behavioral: Measurements of quality within the organization, and tracking compliance with standards and procedures within an organization to ensure efficiency and effectiveness in its operations;

- Evaluation: Measurements of efficiency and effectiveness of procedures and analyses organizational performance per the strategic objectives and goals of the organization.

Generally, data collection for the DOPBE model (Figure 4) was performed through focus group sessions, and the feedback and specific verbatim documented for future analysis. Furthermore, strategic plans, performance reports, resolutions, and administration records generated at four organizational levels were targeted for the study. Subsequently, the strategic level of the organization, operational levels, top management level, activity reports, and records was analyzed and rated based on the following key by using a Likert scale (a scale used to map affinity of individual feedback to a given topic).

Answers for following questions within five pillars were analyzed for objectivity, scope, and knowledge:

Direction:

- Mission, values, and corporate policies (Why?);

- Business strategy and definition of strategic objectives (How?);

- Timeframe and quantification of strategic objectives (When and what?); 
- Integration of business strategy to economic group policies/strategies (How?);

- Action markets (Where?);

- $\quad$ Target customers (Who?);

- Products and services (What?);

- $\quad$ Time to market (When?);

- $\quad$ Products and services placement (How?).

Posture:

- Values and corporate culture;

- Ethical principles;

- Organizational principles and code of conduct;

- Social responsibility principles and code of conduct;

- Environmental principles and code of conduct;

- Principles and codes of professional conduct;

- Principles of relationships with suppliers;

- Principles of action and participation in the community;

- Legal framework of activities.

Organization:

- Organizational structure;

- Integration and compatibility of organizational structure in economic groups;

- Functional diagrams and operational rules;

- Organizational information systems;

- Training and information of employees, suppliers, and subcontractors;

- Planning of activities and resource allocation;

- Strategic business partnerships;

- Business units, geographic action areas, and subsidiaries/branch offices;

- Outsourcing of activities and functions.

Behavior:

- Certifications and sub-systems of management;

- Level of effectiveness (objectives);

- Level of efficiency (resources);

- Productivity levels;

- Internal audits;

- Customers and employee's satisfaction analyses;

- Action on internal faults and complaints;

- Continuous improvement processes;

- Conciliation between strategy and operational actions.

Evaluation:

- Indicators and evaluation metrics;

- Evaluation of results;

- Appraisal between expected and obtained results;

- Monitoring of organizational efficiency;

- Monitoring of organizational effectiveness;

- Economic and markets analyses;

- Adjustment of actions according to results; 
- Forecasting and development of future scenarios and potential markets;

- Strategic realignment procedures.

Scores for each of the queries were analyzed based on the following scale:

- Explicitly defined, well exposed, and applied (Type 5);

- Explicitly defined but insufficiently exposed and applied (Type 4);

- Implicitly defined and collectively recognized (Type 3);

- Implicitly defined but individually recognized (Type 2);

- Undefined, not cleared, or not applied (Type 1);

- Do not know/do not answer/not applicable (Type 0);

- Type 5 denotes an organization with proper disclosure and a satisfactory evaluation from management;

- Type 4 organizations show that management is concerned and wants to improve the disclosure and knowledge effectiveness within an organization;

- Type 3 denotes the gaps in disclosure and knowledge effectiveness within an organization;

- Type 2 organizations have parameters but are susceptible to interpretation, and no general notion of parameters exists within such organizations;

- Type 1 denotes that neither parameters nor competencies are identified or tracked;

- Type 0 denotes the absence of knowledge about organizational sustainability parameters and competencies [45].

Another model to determine the organization sustainability of corporations-this model facilitates the classification of organizations into one of the following six levels:

- Level 0: In such organizations, no steps are taken for sustainability. However, specific steps could be planned or initiated because of regulations such as government legislation on consumer protection. The organizations in this state are generally in a "pre-sustainability" state;

- Level 1: In such organizations, organization sustainability is considered a provision for societies' welfare through actions such as CSR initiatives. Level 1 organizations are generally considered to have taken initial steps to improve organization sustainability;

- Level 2: In such organizations, organizational sustainability is considered in ethical, social, and environmental spheres because it strengthens organization market standing and brand equity, which are directly linked to the economic health of the organization. The primary motivator for Level 2 organizations are the economic benefits from the reputation of the brand;

- Level 3: In such organizations, an organization's sustainability initiatives have matured. These organizations balance their social, economic, and environmental initiatives. Motivations for Level 3 organizations are beyond economic benefits and the well-being of society. Maximizing human potential and the well-being of the planet are critical motivators;

- Level 4: In such organizations, initiatives are implemented to create economic, social, and environmental benefits. Motivations for organizations at Level 4 are based on the knowledge that sustainability is part of the organization's short- and long-term progress; hence, sustainability is inevitable;

- Level 5: In such organizations, sustainability is incorporated into every aspect of an organization to improve the standards of living of its employees, stakeholders, and surrounding community. The motivation occurs because individuals, the community, society, and organizations are interdependent, and a universal responsibility exists regarding sustaining the well-being of others.

All levels include an incremental increase in commitment and resource allocation from the previous level. At Levels 4 and 5, outcomes do not remain as the key motivation; by contrast, the organizations do it as part of their responsibility for society and the community [46]. 


\subsection{Initial Review}

To identify the literature on organizational efficiency measurement, a systematic literature review was carried out. The methodology for the systematic literature review as based on Tranfield et al. (2003). The method is explained as follows and is superior to other methods because the results of the systematic literature review are transparent and reproducible [47].

First, a random search approach, namely, snowballing, was used to identify (i) keywords associated with the theme of "organizational efficiency measurement" and (ii) the most relevant publishers in this domain. This preliminary search was carried out in Google Scholar.

The preliminary search results provided the literature related to governmental efficiency, the profitability of businesses, and managing business operations. However, the book "Organization Effectiveness-a comparison of multiple models," published in 1983, by Kim S. Cameron and David A, was observed. Whetten was one of the first publications to discuss the term "organization efficiency measurement" in a holistic view that covered the efficiency of all aspects of an organization, not solely profitability [48].

To be more systematic, a primary search criterion was developed based on the keywords identified in the initial search. This step helped to limit the search results to the literature available in the English language and to focus on articles peer-reviewed from 1983 until May 2018 (1983 was the first year because of the literature on organizational efficiency). Initial and final search criteria were also established to ensure that articles could be examined based on relevance. Articles based on pharmaceutical companies studies on drug samples/testing/reviews and chemical/medical composition reviews not linked directly with organizational efficiency were excluded.

The systematic search was carried out in the following scientific databases: Science Direct, Springer, Wiley, Sage, Taylor and Francis, JSTOR, Emerald, and Google Scholar. Search parameters are presented in Table 1, with the details of the initial and final criteria employed to identify the relevant articles systematically.

Although the literature helped identify organizational efficiency models and focus areas in an international context, obtaining literature on organizations from the Middle East or Qatar was difficult.

Table 1. Overview of the systematic literature review.

\begin{tabular}{|c|c|c|}
\hline \multicolumn{2}{|c|}{ Steps Taken during the Systematic Review } & Description and Results \\
\hline \multicolumn{2}{|c|}{ Step 1-Keywords } & $\begin{array}{l}\text { Organization Performance, Business Efficiency, Organization } \\
\text { Effectiveness, and Organization Efficiency Measurement }\end{array}$ \\
\hline \multirow{3}{*}{$\begin{array}{l}\text { Step 2-Inclusion, Exclusion } \\
\text { criteria }\end{array}$} & Basic Search Criteria & $\begin{array}{l}\text { - } \quad \text { Language: English } \\
\text { - } \quad \text { Timeline: } 1983 \text { to } 2018 \\
\text { - } \quad \text { Type: Peer review articles }\end{array}$ \\
\hline & Initial Criteria & $\begin{array}{l}\text { - Articles that establish or emphasize organizational } \\
\text { efficiency, efficiency improvement tools are included } \\
\text { - Articles in which organizational efficiency are referred to } \\
\text { but are not the main theme are excluded } \\
\text { - Articles with various dimensions of organization } \\
\text { efficiency and organizational sustainability, efficiency } \\
\text { improvement is included }\end{array}$ \\
\hline & Final Criteria & $\begin{array}{l}\text { - Articles in pharmaceuticals/drug reviews and } \\
\text { chemical/medical composition reviews which are not } \\
\text { linked are excluded }\end{array}$ \\
\hline
\end{tabular}


Table 1. Cont.

\begin{tabular}{|c|c|c|}
\hline \multicolumn{2}{|c|}{ Steps Taken during the Systematic Review } & Description and Results \\
\hline \multicolumn{2}{|c|}{ Step 3-Search database } & $\begin{array}{l}\text { Science Direct, Springer, Wiley, Sage, Taylor and Francis, } \\
\text { JSTOR, Emerald, and Google Scholar }\end{array}$ \\
\hline \multirow{8}{*}{ Step 4-Results Returned } & Science Direct $\left.{ }^{\wedge}\right)$ & 5267 \\
\hline & Springer $^{(+)}$ & 19 \\
\hline & Wiley ${ }^{(*)}$ & 18 \\
\hline & Sage ${ }^{(*)}$ & 7 \\
\hline & Taylor and Francis ${ }^{(*)}$ & 8 \\
\hline & JSTOR $\left.{ }^{(}\right)$ & 317 \\
\hline & Google Scholar $^{(+)}$ & 22 \\
\hline & Emerald $^{(*)}$ & 6 \\
\hline \multicolumn{2}{|c|}{$\begin{array}{c}\text { Step 5-Number of articles selected after the } \\
\text { initial screening }\end{array}$} & 66 \\
\hline \multicolumn{2}{|c|}{ Step 6-Number of articles selected after final screening } & 40 \\
\hline
\end{tabular}

\subsection{Corporate Information on Qatari Organizations}

Based on a review of the available literature and reports on organizational efficiency of organizations in Qatar, the relevant literature is limited, and the real data that shows the efficiency level of Qatari organizations are not accessible. Thus, the author reviewed the information available in the public domain such as annual reports and sustainability reports. Table 2 shows the selected sustainable reports for review from 2015 onward from some of the primary player's organizations in Qatar. The year 2015 was the cut-off year because the data would have been too outdated to have any significance in analyses of organizational efficiency in 2019.

Table 2. Sustainability reports of Qatari organizations considered for review.

\begin{tabular}{lllc}
\hline No & Organization & Industry & Year of Publishing \\
\hline 1 & Qatar Petroleum & Oil and Gas & 2016 \\
2 & Doha Bank & Retail Banking & 2016 \\
3 & Dolphin Energy & Oil and Gas & 2015 \\
4 & Kahramaa & Utilities & 2016 \\
5 & Nakilat & LNG Transportation & 2016 \\
6 & Oryx GTL & Oil and Gas & 2015 \\
7 & Qatar Airways & Aviation & 2016 \\
8 & Qatar Fertilizer Company & Fertilizers & 2016 \\
9 & Qatar Gas & Oil and Gas & 2016 \\
10 & Qatar Steel & Steel Production & 2016 \\
11 & Qatalum & Aluminum Production & 2016 \\
12 & Q Chem & Industrial Chemicals & 2016 \\
13 & Vodafone & Telecom & 2016 \\
14 & Woqood & Fuels & 2016 \\
\hline
\end{tabular}

A full review of the sustainability reports and annual reports demonstrated that few of the reports had relevant content useful for the research and the remainder had partial utility. Table 3 shows the selected annual reports for review from 2015 onwards from some of the primary player's organizations in Qatar. 
Table 3. Annual reports of Qatari organizations considered for review.

\begin{tabular}{lllc}
\hline No & Organization & Industry & Publishing Year \\
\hline 1 & Ahli Bank & Retail Banking & 2017 \\
2 & Al Meera & Retail Stores chain & 2016 \\
3 & Aamal Holdings & Industrial Conglomerate & 2016 \\
4 & Mannai Corporation & Industrial Conglomerate & 2017 \\
5 & Barwa Real estate & Real estate Management & 2017 \\
6 & Commercial Bank & Retail Banking & 2016 \\
7 & Ooredoo & Telecom & 2016 \\
8 & Qapco & Petrochemicals & 2016 \\
9 & Qatar Islamic Bank & Retail Banking & 2016 \\
10 & Qatar Petroleum & Oil and Gas & 2016 \\
11 & Qatar Tourism Authority & Tourism Regulator & 2016 \\
\hline
\end{tabular}

The key elements discussed in this research are the key metrics used to measure the sustainability parameters in Qatari organizations and a comparison with international best practices.

A full review of the sustainability reports and annual reports demonstrated that few of the reports had relevant content useful for the research and the remainder had partial utility. Table 4 shows the selected annual reports for review from 2015 onwards from some of the primary player's organizations in Qatar.

Table 4. Annual reports of Qatari organizations considered for review.

\begin{tabular}{lllc}
\hline No & Organization & Industry & Year of Publishing \\
\hline 1 & Ahli Bank & Retail Banking & 2017 \\
2 & Al Meera & Retail Stores chain & 2016 \\
3 & Aamal Holdings & Industrial Conglomerate & 2016 \\
4 & Mannai Corporation & Industrial Conglomerate & 2017 \\
5 & Barwa Real estate & Real estate Management & 2017 \\
6 & Commercial Bank & Retail Banking & 2016 \\
7 & Ooredoo & Telecom & 2016 \\
8 & Qapco & Petrochemicals & 2016 \\
9 & Qatar Islamic Bank & Retail Banking & 2016 \\
10 & Qatar Petroleum & Oil and Gas & 2016 \\
11 & Qatar Tourism Authority & Tourism Regulator & 2016 \\
\hline
\end{tabular}

The key elements discussed in this research are the key metrics used to measure the sustainability parameters in Qatari organizations and a comparison with international best practices.

\section{Results and Discussion}

The review of annual reports and sustainability reports of Qatari organizations is presented in Tables 2 and 3. Key organizational efficiency indicators used in Qatari organizations that are comparable to international best practices are listed as follows.

\subsection{Air Transport}

Qatar Airways is the national and only airline company in the state of Qatar. The sustainability report published in 2016 differed in its content compared with the reports published by other Qatari organizations because the factors affecting sustainable airline operations differ from the other industries reported on in this research. The key challenges identified by Qatar Airways in their report are (i) cabin waste management, (ii) airport energy management, (iii) aviation fuel efficiency, and (iv) stopping illegal wildlife transportation. Qatar Airways also focusses on five key sustainability elements: (1) Energy and climate change-reducing fuel consumption and emissions, (2) reduction of solid and 
liquid wastage generated by its operations, (3) optimal use of water and land resources, (4) reduction of noise and air pollution from air operations, and (5) environmental conservation [49].

\subsection{Electric Utility}

Qatar General Electricity and Water Corporation (Kahramaa)—the sole power transmission and distribution system owner and operator in the state of Qatar-report key sustainability performance indicators and factors affecting, for example, sustainability. Their sustainability report was published in 2016. Kahramaa launched a sustainability initiative named "Tarsheed" in 2012 to realize a significant reduction in the consumption of water and electricity and in carbon emissions. The program also supports organizations within Qatar to produce electricity from renewable resources and aims to supplement production of electricity, namely, 500 to $700 \mathrm{MW}$ from renewable resources [50].

Some key performance indicators used by Kahramaa to measure sustainability are as follows:

Electricity Production/Supply

- Amount of electricity received from the power-generating units and sent to the grid for customers (gigawatt hour-GWh);

- $\quad$ Peak Demand-KWh (kilowatt hour);

- Average duration of power interruption per customer (Frequency/duration in minutes);

- Transmission losses (gigawatt hour-GWh).

Water Supply Operations

- Total annual production of water-Million cubic meter $\mathrm{MM}^{3}$;

- Number of pipe bursts per $100 \mathrm{KM}$;

- Per capita water and electricity consumption (liter per head per day/watt-hour per person per month);

- $\quad$ Savings in potable water consumption for other uses through using treated sewage effluent (TSE).

Human Resource Management

- $\quad$ Turnover rate \%;

- Percentage of females employed concerning the total number of employees;

- Percentage of Qatari nationals employed concerning the total number of employees;

- Number of Qatari students sponsored for studies in local and international institutions;

- Total hours of training provided to full-time employees.

Health Safety and Environment

- Recycled waste as a percent of total waste generated;

- $\mathrm{CO}_{2}$ emissions in tons;

- Number of fatalities per year;

- Number of reported injuries and frequency;

- Total hours lost because of injuries.

Financial Indicators

- Total Revenue-QAR;

- Total operating cost-QAR;

- Gross/Net profit-QAR;

- Percentage of procurement spent on local suppliers;

- Total gross assets-QAR. 
These indicators identify the nature of sustainability reporting and benchmark the parameters compared with the KPIs reported for peers internationally [50].

\subsection{Oil and Gas}

Qatar Petroleum (QP) is the national oil company of Qatar and responsible for managing the oil and gas resources of the state of Qatar. QP is engaged in the exploration, production, refining, sales, and marketing of oil, liquefied natural gas, natural gas liquids, gas to liquids, petrochemicals, steel, aluminum, and fertilizers through a matrix of organizations operating within the QP umbrella. QP operates various onshore and offshore production/refining facilities along with manufacturing complexes across Qatar. QP is also engaged with international partners for exploration, production, and refinement of petroleum products through various subsidiaries. QP underwent significant structural changes to optimize their operations in 2015, which resulted in QP becoming a robust and efficient organization. QP aims to manage Qatar's hydrocarbon resources efficiently and in a cost-effective manner and develop a capable and motivated workforce by emphasizing the development of the Qatari citizen. The main objectives of QP were to excel in the safe delivery of projects and achieve excellence in managing assets and their functions effectively, including contractual obligations with partners, while ensuring implementation of best-in-class health safety and environment protocols. QP identified the following focus areas as core enablers to achieve efficiency and sustainability for the organization [51].

The health and safety of the QP workforce is of paramount importance to the company. The productivity loss associated with health and safety problems and violations is tracked using the lost time injury frequency rate (LTIFR), which was 0.07 for 2016 despite the objective being set for 0.1 for 2016. This achievement was significant for the reduction of lost time because the number of injuries was below the set target. Primary factors that were the impetus for this achievement were strict follow up on and enforcement of safety policies at worksites, frequent and periodic refresher trainings, and robust reward and recognition programs that encouraged participation in and compliance with health and safety regulations and protocols.

Business continuity management systems is another crucial area that QP management was working on rigorously to ensure that processes and systems were in place for disaster recovery and resumption of operations in the shortest possible period. Business continuity resource plans for core business operations and support services were tested and implemented, resulting in achieving ISO 22301 certification for business continuity management. The crisis management plan and control center was established along with a crisis management committee to manage crises involving QP, its subsidiaries, or JVs effectively.

Energy efficiency is another core area for QP, and their utilization of energy has been tracked meticulously to reduce energy consumption significantly. Managing helicopter logistics for offshore operators and sharing logistics and resources are essential projects in their energy efficiency program. Direct energy consumption in QP decreased from 81 million gigajoules in 2015 to 68 million gigajoules in 2016, in significant cost savings and positive environmental impacts.

Employee satisfaction and well-being are key focal areas for QP. The launch of behavioral training programs for staff, fitness to work examinations and training sessions on stress/work life balance as part of worker's welfare, and various sporting events for employees underlines the importance attributed by QP management to worker's welfare.

The environment and climate change are also areas of importance for QP. This company has implemented various measures to enforce the policy of reduction in flaring during exploration and zero flaring during regular production. Recovery of boil-off gas at Jetty is also implemented to reduce carbon emissions from LNG transportation. A key metric used to measure $\mathrm{CO}_{2}$ emissions is "carbon emissions per ton of hydrocarbon produced," a global metric used by oil and gas producers/refiners. $\mathrm{QP}$ also uses this metric to track carbon emissions. 
Managing water resources, reducing waste, increasing recycling, and, in turn, contributing to nature conservation is now a priority at QP. Reduction in total waste and recycling up to $32 \%$ of total waste are critical milestone achieved by QP in 2016.

Empowering the community through providing education, training, and subsequently, employment opportunities has been the cornerstone of QP's Qatarization program. QP also supports various training programs for Qatari nationals and expatriates within its subsidiaries and JVs to achieve their full potential in career development [51]

In summary, QP has been an essential catalyst in the socioeconomic development of Qatar's growth story.

Oryx GTL—a downstream oil and gas company in Qatar-focused on producing diesel, cooking gas, and naphtha through gas to liquids processes published in their sustainability report in 2016 in compliance with GRI's G4 standards. The materiality matrix of Oryx GTL identifies the top 20 most important topics of interest to the organization and various stakeholders [52] in Table 5.

Table 5. Topics identified as per the materiality matrix.

\begin{tabular}{ll}
\hline Worker's health and safety & Contribution to the national economy \\
Governance and legal compliance & Product and service quality \\
Production/Output & Human Rights \\
Process safety/emergency management & Emissions \\
Flaring (effluent gas burning process) & Effluent Management \\
Business ethics & Managing oil spills \\
Qatarization & Water Management \\
Financial growth & Energy efficiency \\
Employment creation & Welfare of the workforce and employee engagement \\
\hline
\end{tabular}

Oryx GTL implemented the European Quality Management Framework (EFQM) to address these materiality challenges. The EFQM framework examines baseline excellence levels within an organization based on their fundamental excellence parameters such as (1) value addition to customers; (2) creating a sustainable future; (3) organizational capability; (3) creativity and innovation; (4) leading with vision, integrity, and inspiration; (5) managing with agility; (6) talent of individuals; and (7) sustaining outstanding results. Once the baseline is established, and gaps are identified in performance improvement, measures are employed to bridge gaps and achieve the intended outcomes as per the EFQM framework.

Q Chem-Qatar Chemicals Company-is a Qatari petrochemical raw material production company engaged in the production and distribution of high density and medium density polyethylene (HDPE and MDPE), olefins, and sulfur. The study analyzed the sustainability report published in 2016 by $Q$ Chem, which also follows GRI's sustainability reporting standards. The materiality matrix of $Q$ Chem identifies (i) employees and contractor's health and safety, (ii) process safety, (iii) Qatarization, (iv) compliance with regulations, and (v) operational excellence as the top five challenges identified as the most important factors for the organization and its stakeholders [53].

A comparison of the materiality matrices of various oil and gas companies with organizations operating in similar downstream domains reveals a similarity in the critical issues identified in the materiality matrix. This is evident from the list of issues identified in the materiality matrices of Oryx GTL and Q Chem.

\subsection{Retail Banking}

Doha Bank, a major retail bank in Qatar, in their sustainability report published in 2016, identifies six critical stakeholders for their sustainability initiatives: Customers, environment, employees, shareholders, community, and suppliers. Doha Bank also identified the key challenges in their operations [54]. The list of critical challenges identified by the bank as per their materiality matrix is as follows: 
- Customer satisfaction and data privacy;

- Regulatory compliance;

- Access to financial services;

- Responsible communication;

\subsection{Steel Manufacturing}

According to the Qatar Steel sustainability report for 2016, its core operations are steel production across rebar, billets, iron briquettes, and direct reduced iron. Qatar Steel operates five direct reduction steel plants, five plants dedicated casting units, and two rolling mills, which have a combined capacity of production of over 22,000 tons of steel per day [55].

Qatar Steel has established a sustainability framework that focusses on the following key areas: The top challenges faced by Qatar Steel are identified in Table 6 .

Table 6. Qatar Steel identified the top 20 challenges for the organization as part of the materiality assessment.

\begin{tabular}{ll}
\hline Sustain financial performance & Contractor safety \\
Employee safety & Product traceability \\
Product quality & Operational efficiency \\
Product innovation & Occupational health \\
Customer satisfaction & Qatarization \\
Emergency response preparedness & Corporate governance \\
Waste management and recycling & Water consumption \\
Energy consumption & Training and development \\
Greenhouse gases emission & Performance-based compensation and rewards \\
Risk Management & Strategic investments \\
\hline
\end{tabular}

- Make steel matter-improving use of steel across various domains;

- Contribute to Qatar's development;

- Reduce environmental impact through its operations;

- Ensure a safe and healthy work environment for its employees and contractors;

- Develop a high performing and motivated team of employees;

- Instill good governance and accountability;

- Achieve profitable growth.

Qatar Steel also has a plan for achieving its sustainability goals, as follows, which are attached to the focus areas to be achieved by 2020: (i) Sustainable steel supplier of choice in the region, (ii) breakthrough low carbon footprint for the steel industry, (iii) world-class energy consumption rates for the steel industry, (iv) leader in recycling and reusing among companies in the Qatar energy and industry sector, (v) zero-harm culture and performance of its employees, and (vi) leading water management practices for Qatar and the steel industry internationally [5].

The best practices employed for improving the operational efficiency of globally renowned steel companies such as POSCO could be emulated by organizations such as Qatar Steel for their continuous improvement programs.

\section{Conclusions}

Based on the search of the available literature and reports on efficiency of organizations in Qatar, the relevant literature was evidently limited, and the real data that shows the efficiency level of Qatari organizations was not accessible; hence, the authors relied on reviewing the information available in the public domain such as in annual reports and sustainability reports. Based on reports published in the annual reporting and sustainability reporting category by Qatari organizations, the author consolidated the general set of organization efficiency indicators reported by Qatari organizations. These indicators 
also indicate the broader challenges such organizations and their stakeholder community must manage, which could be a premise for further research.

Achieving desired goals of an organization through its operations and organization culture characters depend on the appropriate use of their resources and efficient production of goods/services meeting the requirements/expectations of its customers-these efforts for achieving organization goals could cause conflicts within organizations. There would be many conflicts within an organization; conflicts between effectiveness and efficiency play a significant role in an organization's success.

Figure 5 highlights the need for further research to establish a framework for organizational efficiency improvement for Qatari organizations. Although the best practices employed to improve the operational efficiency of globally renowned organizations could be emulated by organizations in Qatar for their continuous improvement programs, in some areas the processes deviate from this standard because of the inequitable nature of the nation's prevailing traditions, customs, and organization culture.

\begin{tabular}{l|l|}
\hline \multicolumn{1}{|c|}{ Customers } & Environment \\
\hline - Data Privacy & - Energy \\
- Customer & consumption \\
- Satisfaction & - Water \\
- Responsible & consumption \\
Communication & - Waste \\
- Access to & Management \\
- quality services & \\
- Regulatory & \\
Compliance & \\
- Customer & \\
Safety & \\
& \\
& \\
& \\
& \\
\end{tabular}
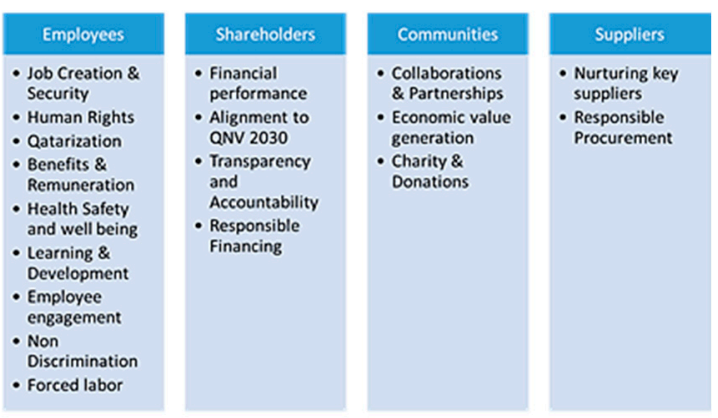

Figure 5. Common stakeholders and critical challenges of the stakeholder community in Qatari organizations.

To develop a comprehensive framework for organization efficiency improvement, further research must identify root causes of the inefficiencies in Qatari organizations, which then must be addressed through suitable mitigation plans to improve overall efficiency. To identify the root causes, general surveys targeted at a sample population of employees of Qatari organizations along with a interviews of industry champions and academicians will be conducted. Once the causes are identified, suitable mitigation plans will be devised and a framework for efficiency improvement for Qatari organizations will be developed. These steps constitute the scope for further research.

Some authors treat efficiency and effectiveness as independent concepts while few define them as complementary to each other for the success of the organization [56]. The ambiguity in applications of these concepts also leads to further complexity of the topic of Organizational Efficiency Improvement in Qatari Organizations. The gaps in literature review opens up an avenue for further research and facets of these issues could be addressed through further research.

Author Contributions: Abdulla S. Al-Shaiba designed the study and wrote the manuscript; Sami G. Al-Ghamdi and Muammer Koc designed, supervised the study, reviewed and approved the final manuscript.

Funding: This research was supported by a scholarship from Ministry of Education and Higher Education, State of Qatar.

Conflicts of Interest: The authors declare no conflict of interest.

\section{References}

1. O'Donnell, O.; Boyle, R. Understanding and Managing Organisational Culture; Institute of Public Administration: Dublin, Ireland, 2008; ISBN 978-1-904541-75-2.

2. Corporate Knights. The results for the 2017 Global 100 Most Sustainable Corporations in the World index. 2015. Available online: https://www.corporateknights.com/magazines/2015-global-100-issue/2015-global100-results-14218559/ (accessed on 29 May 2016). 
3. Qatargas. Forging Lasting Relationships Building on Qatargas' reputation for safety, flexibility andreliability. Available online: https:/www.qatargas.com/english/MediaCenter/The\%20Pioneer/The\%20Pioneer\%20\%20Quarter\%203,\%202016.pdf (accessed on 2 August 2016).

4. Posco. Integrated Report of Economic, Environmental and Social Sustainability. Posco Report 2016. Available online: http://www.posco.com/homepage/docs/eng5/dn/sustain/customer/2016_POSCO_Report_EN.pdf (accessed on 29 May 2016).

5. Qatar Steel. Sustainbility Report; Qatar Steel: Mesaieed, Qatar, 2016.

6. Fysikopoulos, A.; Pastras, G.; Theocharis Alexopoulos, T.; Chryssolouris, G. On a generalized approach to manufacturing energy efficiency. Int. J. Adv. Manuf. Technol. 2014, 73, 1437-1452. [CrossRef]

7. Pinprayong, B.; Siengtai, S. Restructuring for organizational efficiency in the banking sector in Thailand: A case study of siam commercial bank. J. Psychol. Bus. 2012, 8, 29-42.

8. Henri, J. Performance Measurment and Organizational Effectivness Bridging the Gap. Manag. Financ. 2004, 30, 93-123.

9. Brovkin, V.; Sitch, S.; von Bloh, W.; Claussen, M.; Bauer, E.; Cramer, W. Role of land cover changes for atmospheric $\mathrm{CO}_{2}$ increase and climate change during the last 150 years. Glob. Chang. Biol. 2004, 10, 1253-1266. [CrossRef]

10. Lewis, H.F.; Lock, K.A.; Sexton, T.R. Organizational capability, efficiency, and effectiveness in Major League Baseball: 1901-2002. Eur. J. Oper. Res. 2009, 197, 731-740. [CrossRef]

11. Bartuševičienè, I.; Šakalytė, E. Organizational Assessment: Effectiveness Vs. Efficiency. Soc. Transform. Contemp. Soc. 2013, 2013, 45-53.

12. Henry, E.A. Is The Influence of Organizational Culture on Organizational Effectiveness Universal? An Examination of The Relationship in The Electronic Media (Radio) Service Sector in The English Speaking Caribbean; Nova Southeastern University: Broward County, FL, USA, 2011.

13. Federman, M. Essay: Towards An Effect-Ive Theory of Organizational Effectiveness. 2006. Available online: https://www.google.ch/url?sa=t\&rct=j\&q=\&esrc=s\&source=web\&cd=2\&cad=rja\&uact=8\&ved= 2ahUKEwiFjuPM-aTlAhVQ3qQKHf0vDf0QFjABegQIAhAC\&url=http\%3A\%2F\%2Findividual.utoronto. ca\%2Fmarkfederman\%2FTowards_an_Effective_Theory_of_OE_Seminar.doc\&usg=AOvVaw3yNRXINUuBhK1MDOIs7hd (accessed on 27 May 2016).

14. Cameron, K. Measuring Organizational Effectiveness In Institutions Of Higher Education. Adm. Sci.Q. 1978, 23, 604-632. [CrossRef]

15. Mccann, J. Organizational Effectiveness: Changing Concepts For Changing Environments. Hum. Resour. Plan. 2004, 27, 42.

16. Balduck, A.L.; Buelens, M. A Two-Level Competing Values Approach to Measure Nonprofit Organizational Effectiveness. 2008. Available online: http://wps-feb.ugent.be/Papers/wp_08_510.pdf (accessed on 27 April 2017).

17. Kilmann, R.H.; Herden, R.P. Towards Systemic Methodology For Evaluating The Impact Of Interventions On Organizational Effectiveness. Acad. Manag. Rev. 1976, 1, 87-98. [CrossRef]

18. Hoy, F.; Hellriegel, D. The Kilmann and Herden Model of Organizational Effectiveness Criteria for Small Business Managers. Acad. Manag. J. 1982, 25, 308-322.

19. Schermerhorn, J.A. Organizational Behavior; John Wiley \& Sons, Inc.: Hoboken, NJ, USA, 2002.

20. Ashraf, G.; Abd Kadir, S. bte A review on the models of organizational effectiveness: A look at Cameron's model in higher education. Int. Educ. Stud. 2012, 5, 80-87. [CrossRef]

21. Bass, B.M. From transactional to transformational leadership: Learning to share the vision. Organ. Dyn. 1990, 18, 19-31. [CrossRef]

22. Tuttle, S.S. Planning and Measurement in Your Organization of the Future; Industrial Engineering and Management Press: Norcross, GA, USA, 1989.

23. Higgins, R. Organizational transformation What is it, why do it, and how? 2010. Available online: https:/www.opm.gov/policy-data-oversight/performance-management/reference-materials/ historical/planning-and-measurement-in-your-organization-of-the-future/ (accessed on 29 August 2018).

24. Yilmaz, C.; Ergun, E. Organizational culture and firm effectiveness: An examination of relative effects of culture traits and the balanced culture hypothesis in an emerging economy. J. World Bus. 2008, 43, 290-306. [CrossRef] 
25. Wright, P.M.; Dunford, B.B.; Snell, S.A. Human resources and the resource based view of the firm. J. Manage. 2001, 27, 701-721. [CrossRef]

26. Marimuthu, A. Human Capital Development and Its Impact on Firm Performance: Evidence From Developmental Economics. J. Int. Soc. Res. 2009, 2, 265-272.

27. Alnasseri, N.; Osborne, A.; Steel, G. Organizational Culture, Leadership Style and Effectiveness: A Case Study of Middle Eastern Construction Clients. In Proceedings of the 29th Annu ARCOM Conference, Reading, UK, 2-4 September 2013; pp. 393-403.

28. William, B. (Ed.) Managing Transition: Making the most of Change; Da Capo Lifelong Books: Boston, MA, USA, 2010.

29. Estalaki, K.G. On the impact of organizational structure on organizational efficiency in industrial units: Industrial units of Kerman and Hormozgan Provinces. 2017. Available online: https://www.researchgate.net/publication/321927740_On_the_impact_of_organizational_structure_on_ organizational_efficiency_in_industrial_units_industrial_units_of_Kerman_and_Hormozgan_provinces (accessed on 11 August 2016).

30. Scott, D.; Bishop, J.W.; Chen, X. an Examination of the Relationship of Employee Involvement With Job Satisfaction, Employee Cooperation, and Intention To Quit in U.S. Invested Enterprise in China. Int. J. Organ. Anal. 2003, 11, 3-19. [CrossRef]

31. Greenberg, J. The intellectual adolescence of organizational justice: You've come a long way, maybe. Soc. Justice Res. 1993, 6, 135-148. [CrossRef]

32. Choudhry, N.; Philip, P.J.; Kumar, R. Impact of Organizational Justice on Organizational Effectiveness. Ind. Eng. Lett. 2011, 1, 18-25.

33. Cohen, W. Drucker on Leadership: New Lessons from the Father of Modern Management; Jossey-Bass: San Francisco, CA, USA, 2010.

34. Pasmore, W.; Wiley, C.; Lacey, A.; Luff, D.; Arham, A.F.; Authors, F.; Corriere, M.A.; Rosenbloom, D.H.; Crewson, P.E.; DeBerry, S.L.; et al. The Relationship between Leadership, Effectiveness and Organizational Performance. Cent. Creat. Leadersh. 2014, 11, 1-28.

35. Khan, R.A.G.; Khan, F.A.; Khan, M.A. Impact of Training and Development on Organizational Performance. Glob. J. Manag. Bus. Res. 2011, 11, 63-69.

36. Schultz, T.W. Human Capital: Policy Issues and Research Opportunities. 1972. Available online: https: //core.ac.uk/download/pdf/6908045.pdf. (accessed on 12 September 2017).

37. Harbison, F. Educational Planning and Human Resource Development; UNESDOC: Paris, France, 1967.

38. Bing, J.; Gardelliano, S. Team Building at the United Nations Industrial Development Organization; UNIDO: Vienna, Austria, 2005.

39. Sharma, V.C.; Jain, T.K. Leadership Practices in India and the USA. ADR J. 2016, 3, 7-10.

40. Rudnick, M.; Kouba, W. Is Transforming Employee ( Hint: It has nothing to do with search). 2006. Available online: https://robertoigarza.files.wordpress.com/2008/11/rep-how-the-google-effect-istransforming-employee-communications-ww-2006.pdf (accessed on 12 September 2017).

41. Jones, J.L.S.; Linderman, K. Process management, innovation and efficiency performance: The moderating effect of competitive intensity. Bus. Process Manag. J. 2014, 20, 335-358. [CrossRef]

42. Visser, W. Corporate sustainability and the individual: A literature review. 2007. Available online: http://www. waynevisser.com/wp-content/uploads/2007/05/paper_sustainability_individual_lit_wvisser.pdf (accessed on 13 March 2017).

43. Porter, M.E.; Kramer, M.R. The Big Idea: Creating Shared Value. Harv. Bus. Rev. 2011, 89, 62-77.

44. Anderson, C.; Brown, C.E. The functions and dysfunctions of hierarchy. Res. Organ. Behav. 2010, 30, 55-89. [CrossRef]

45. Santos, J.R.; Anunciação, P.F.; Svirina, A. A Tool To Measure Organizational Sustainability Strength. 2013. Available online: https://core.ac.uk/download/pdf/62691770.pdf (accessed on 14 February 2018).

46. Cella-de-oliveira, F.A. Indicators of Organizational Sustainability: A Proposition From Organizational Competences. Int. Rev. Manag. Bus. Res. 2013, 2, 962-979.

47. Tranfield, D.; Denyer, D.; Smart, P. Towards a Methodology for Developing Evidence-Informed Management Knowledge by Means of Systematic Review. Br. J. Manag. 2003, 14, 207-222. [CrossRef]

48. Cameron, K.S.; Whetten, D.A. Organizational Effectiveness and Quality: The Second Generation. Handb. Theory Res. 1996, XI, 265-306. 
49. Qatar Airways. Sustainbility Report; Qatar Airways: Mesaieed, Qatar, 2017.

50. Kahramaa. Sustainbility Report; Kahramaa: Doha, Qatar, 2016.

51. QP Annual Review. Qatar Pet. 2016, 91, 399-404.

52. Oryx GTL Limited. Committed to Excellence. 2016. Available online: http://www.oryxgtl.com.qa/ sustainability-reports/Oryx_Sustainability_Report_V6.pdf (accessed on 14 February 2018).

53. Qchem. Sustainbility Report; Qchem: Mesaieed, Qatar, 2016.

54. Doha Bank. Sustainbility Report; Doha Bank: Doha, Qatar, 2016.

55. Qatar Steel. Sustainbility Report. 2015. Available online: https://www.qatarsteel.com.qa/wp-content/ uploads/2016/12/sustainability-Report-2015.pdf (accessed on 14 February 2018).

56. Tretyakov, S. Business Operations between Efficiency and Effectiveness. J. Inf. Organ. Sci. 2014, 30, $251-262$.

(C) 2019 by the authors. Licensee MDPI, Basel, Switzerland. This article is an open access article distributed under the terms and conditions of the Creative Commons Attribution (CC BY) license (http://creativecommons.org/licenses/by/4.0/). 